\title{
Apresentação \\ VI JORNADA DE HISTÓRIA DA CIÊNCIA E ENSINO: PROPOSTAS, TENDÊNCIAS E CONSTRUÇÃO DE INTERFACES
}

A VI Jornada de História da Ciência e Ensino será realizada na Universidade Federal de Juiz de Fora - UFJF, na cidade de Juiz de Fora - MG, com apoio do departamento de Química e colaboração do Programa de Estudos Pós-Graduados em História da Ciência e do Centro Simão Mathias de Estudos em História da Ciência - CESIMA, da Pontifícia Universidade Católica de São Paulo - PUC/SP, no período de 28 a 30 de setembro de 2017. O principal objetivo do evento é possibilitar a integração entre professores da Educação Básica, Ensino Superior e Estudantes de Graduação e Pós-Graduação das áreas da Saúde, Humanas, Biologia, Química, Física e Matemática tendo como foco assuntos diversos da área de História da Ciência, permitindo uma aproximação entre a comunidade escolar, instituições de pesquisa e universidades.

O encontro visa também instrumentalizar os professores das mais diversas áreas de Ciências Naturais, Humanas e da Saúde, no sentido de fornecer subsídios para que possam atender as legislações e as resoluções normativas da educação brasileira, as quais cobram uma significativa inserção da História da Ciência em todos os níveis de ensino. Dentro das atividades do evento teremos Minicursos e Workshops, fornecidos por pesquisadores de destaque na área; Comunicações Orais, com os trabalhos selecionados na modalidade relatos de pesquisa; Pôsteres, formato este em que todos os trabalhos aprovados serão apresentados. Nesta edição, acrescentamos a modalidade Roda de Conversa, na qual serão contemplados os relatos de experiência dos professores sobre as atividades relacionadas à história da ciência aplicadas em sala de aula.

Esperamos que esta VI edição, primeira a ser sediada fora da PUC-SP onde o evento surgiu em 2007, possa atender as expectativas e manter a qualidade e impacto das demais edições. 


\author{
Comissão organizadora \\ Fernanda Luiza de Faria - UFJF \\ Fumikazu Saito - PUC/SP \\ Ingrid Nunes Derossi - UFJF \\ Ivoni de Freitas Reis - UFJF \\ Joao Batista Alves dos Reis - UNEC \\ Jomara Mendes Fernandes - UFJF \\ Jose Guilherme da Silva Lopes - UFJF \\ Marcelo Fonseca Pinto - UFJF \\ Maria Helena Roxo Beltran - PUC/SP \\ Sandra de Oliveira Franco Patrocínio - UFJF \\ Vinícius da Silva Carvalho - UFJF
}

\title{
Comitê científico
}

$$
\begin{gathered}
\text { Ana Maria Alfonso-Goldfarb - PUC/SP } \\
\text { Deividi Marcio Marques - UFU } \\
\text { Fumikazu Saito - PUC/SP } \\
\text { Gilson Leandro Queluz - UTFPR } \\
\text { Ivoni de Freitas Reis - UFJF } \\
\text { Joao Batista Alves dos Reis - UNEC } \\
\text { Lais dos Santos Pinto Trindade - PUC/SP } \\
\text { Márcia Helena Mendes Ferraz - PUC/SP } \\
\text { Maria Cristina Araújo de Oliveira - UFJF } \\
\text { Maria Helena Roxo Beltran - PUC/SP } \\
\text { Nadja Paraense dos Santos - UFRJ } \\
\text { Natalina Aparecida Laguna Sicca - CUML } \\
\text { Olival Freire Junior - UFBA } \\
\text { Ourides Santin Filho - UEM } \\
\text { Paulo Alves Porto - USP }
\end{gathered}
$$

